\title{
Criteria to Determine Intestinal Microbiota Donor and Procedure to Transplant It by Jejunum or Colon
}

ISSN: 2637-7632

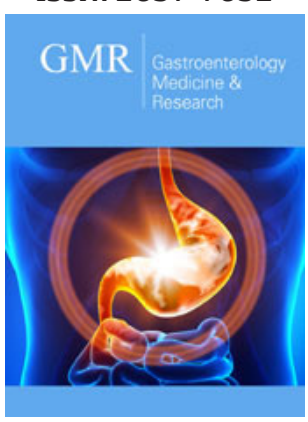

For HTML Version scan this QR code:

${ }^{* 1}$ Corresponding author: Álvaro Zamudio Tiburcio, Department of Gastroenterology, México

Submission: 眥 February 25, 2019

Published: : March 06, 2019

Volume 3 - Issue 1

How to cite this article: Álvaro Z-T, Héctor B-R, Pedro A R-L. Criteria to Determine Intestinal Microbiota Donor and Procedure to Transplant It by Jejunum or Colon. Gastro Med Res. 3(1). GMR.000552. 2019.

DOI: 10.31031/GMR.2019.03.000552

Copyright@ Álvaro Zamudio Tiburcio, This article is distributed under the terms of the Creative Commons Attribution 4.0 International License, which permits unrestricted use and redistribution provided that the original author and source are credited.

\author{
Álvaro Zamudio-Tiburcio ${ }^{1 *}$, Héctor Bermúdez-Ruiz² and Pedro Antonio Rey- \\ es-López ${ }^{3}$ \\ ${ }^{1}$ Department of Gastroenterology, México \\ ${ }^{2}$ Department of Endoscopy, México \\ ${ }^{3}$ Department of Cardiology, México
}

Keywords: Intestinal microbiota transplant donors, Donors of fecal microbiota transplantation, Intestinal microbiota transplantation (IMT)

\section{Who can be a Donor?}

Be younger than 30 years old, not obese, not diabetic, without intestinal surgeries and have not taken antibiotics in the last 6 months. Make a complete clinical history. If you are a potentially healthy donor, request: Entamoeba Histolytica; Giardia Lamblia; Blastocystis Hominis; Dientamoeba Fragilis: Coproculture. Stool Rotavirus and Adenovirus Antigen (Adenoviruses Antigens of Rotavirus Antigens). C. difficile (Toxin A and B). VDRL. Profile of Hepatitis A, B and C. Antibodies of human immunodeficiency virus 1 and 2. Presumptive test. Antibodies Anti-Cytomegalovirus IgG. Epstein-Barr IgG antibodies. Immunoglobulin profile: Immunoglobulin $\mathrm{A}$, immunoglobulin $\mathrm{E}$, immunoglobulin $\mathrm{M}$ and immunoglobulin $\mathrm{G}$. The questioning should include search for: Inflammatory bowel disease, colonic polyps, irritable bowel syndrome and consider that the donor exercise.

\section{Clinical Exclusion Criteria to the Donor}

AIDS, Hepatitis B and C. Not having been in prison or being individuals at high sexual risk. No tattoos, or piercings, or have been traveling for the last 6 months in countries with diarrheal diseases or high risk of traveler's diarrhea, as well as not using illicit drugs. Have not a contagious disease. No Major surgery of the digestive system, inflammatory bowel disease, irritable bowel syndrome, chronic constipation or chronic diarrhea. Multiple sclerosistype autoimmune diseases, connective tissue diseases. Atopic diseases (asthma, eczema, eosinophilic pathologies of the gastrointestinal tract) [1].

\section{History of Gastrointestinal Malignancy}

1. Use of antibiotics in the last 6 months. Use of immunosuppressive medication. Use of antineoplastic treatment.

2. Obesity (BMI> 30), metabolic syndrome, diabetes mellitus type 1;

3. Obesity (BMI> 30), diabetes mellitus type 2. Chronic pain syndromes (Fibromyalgia, Chronic fatigue syndrome).

\section{Microbiota for Jejunal Administration}

In a laminar flow hood, we mixed 4 hours before the transplant 60grams of feces with 500 milliliters of water. We homogenize, in blender. We filtered the mixture through sterile gauze (3 layers) and, we deposited 500 milliliters of aliquot in sterile plastic bottle, closing 
at the end, with rubber stopper. Place the hypodermic needle of the number 18 inside the cap of the bottle for 5 seconds to extract the gas produced and remove the needle. If the aliquot is not used immediately, it can be refrigerated. The bottle should remain upright. This mixture is the microbiota. The approach of IMT with frozen stools entails a series of advantages by eliminating fecal odor, reducing the volume instilled and opening the possibility of future donor stool banks to guarantee the preservation of the microbiota.

\section{Microbiota for Administration by Colon}

In a laminar flow hood, we mixed 4 hours before the transplant, 180 grams of feces with 500 milliliters of water. The rest of the preparation is the same as for jejunum administration..

\section{References}

1. Li SS, Zhu A, Benes V, Costea PI, Hercog R, et al. (2016) Durable coexistence of donor and recipient strains after fecal microbiota transplantation. Science 352(6285): 586-589.

For possible submissions Click below: 